\section{TRYPANOSOMIASIS IN WOLF (CANIS LUPUS) - A CASE STUDY FROM LUCKNOW ZOO}

\section{Utkarsh Shukla}

Deputy Director, Lucknow Zoo, Lucknow, Uttar Pradesh 226001, India.

Trypanosomiasis due to Trypanosoma evansi has been reported in wolves under captivity at Calcutta (Sengupta, 1974). Ziauddin et al. $(1992 \mathrm{a}, \mathrm{b})$ recorded trypanosomiasis in a wolf in Mysore Zoo. There are very few reports of trypanosomiasis in wolves.

Lucknow Zoo, one of the oldest zoos in the country, has not maintained complete records of cases of trypanosomiasis in wolves. Only one case in a male wolf was recorded on 9 March 2000 by Ashok Kashyap. This report represents the history, clinical symptoms, treatment and method of prophylaxis against trypanosomiasis in wolves at the zoo.

On 15 March 2001 the keeper reported that a female wolf of paddock - 1 refused meat and looked dull and depressed. It was also noted that the wolf was taking more than the normal time to consume her meal for the last two days. Her belly was so enlarged that the keeper suspected the wolf to be pregnant. The prominent symptoms were fever $\left(103.4^{0} \mathrm{~F}\right)$, enlargement of the abdomen (tentatively the enlargement of the liver) and edema of the hind limbs. The wolf was dull, anorexic, severely anaemic, weak, trembling hind limbs and she could not stand properly. She passed stools with blood. She weighed only $13 \mathrm{~kg}$.

Examination of blood smears (collected from the cephalic vein) at the central laboratory of the Animal Husbandry Department (U.P.) revealed large numbers of Trypanosoma. Treatment was started immediately with 4.4' Diamidinodiozo aminobenzene diaceturate tetrahydrate (Berenil; Hoechst Roussel Vet.), at the rate of $0.8 \mathrm{~g} / 100 \mathrm{~kg}$ body weight. Supportive therapy with hematinics and fluid therapy with $20 \%$ dextrose $13 \mathrm{ml} / \mathrm{kg}$ body weight $(100 \mathrm{ml})$ for three days was also started simultaneously in order to treat hypoglycemia evident from physical examination. Conventional therapy for hepatomegally was also attempted with liver extract injections (Neohepatex; Biological E Limited). The same treatment was repeated after 48 hours with half the initial dose. The very next day, the wolf responded to the medication and completely consumed the offered meal. On 20 March 2001, post treatment examination of blood smears revealed the absence of the blood protist. Blood smears were taken several times and on 26 March 2001 blood smears revealed that a small number of Trypanosoma were still present. Treatment was started after positive diagnosis on the same day with Quinapyramine sulphate (Triquin-S; Wockhardt Veterinary Ltd.) at the dose rate of $5 \mathrm{mg} / \mathrm{kg}$ body weight. Supportive therapy was also initiated at the same time with fluid therapy with Rintose at $13 \mathrm{ml} / \mathrm{kg}$ body weight $(100 \mathrm{ml})$ for three days in order to cope with hypoglycemia. Conventional therapy for hepatomegally was also attempted with liver extract injections (Neohepatex; Biological E Limited). After treatment for 20 days with supportive therapy including liver extract, symptoms like fever, edema of hind limbs and enlargement of the abdomen reduced dramatically. The microscopical examination of nine blood smears (which were taken every alternate day) revealed the absence of Trypanosoma in the blood. The wolf began to take normal diet. Prophylactic treatment of all the wolves in paddock - 1 and paddock - 2 (total 6 wolves) with Quinapyramine sulphate and chloride (Triquin$\mathrm{S}$; Wockhardt Veterinary Ltd.) prevented the spread of trypanosomiasis.

\section{References}

Sengupta, M.R. (1974). A preliminary report on diseases and parasites of zoo animals, birds and reptiles. Indian Journal of Animal Health 13: 15-24.

Ziauddin, K.S., K. Mudidharan and S.J. Seshadri (1992a). Some pathological observations on Trypanosomiasis in a tigress at Mysore Zoo. Indian Journal of Wildlife Health and Management 1(1): 38-39.

Ziauddin, K.S., K. Murlidharan and S.J. Seshadri (1992b). Trypanosomiasis in a wolf at Mysore Zoo. Indian Journal of Wildife Health Management 1(1): 47. 